\title{
Impacts of red imported fire ants Solenopsis invicta on survivorship of hatchlings of the broad-snouted caiman Caiman latirostris
}

María V Parachú Marcó ${ }^{1,2^{*}}$, Alejandro Larriera ${ }^{2,3}$ and Carlos I Piña $a^{1,2,4,5}$

\begin{abstract}
Background: Oviparous vertebrate species are often vulnerable to predation by red imported fire ants (RIFAs, Solenopsis invicta) in natural environments. The necrotic action of the venom can cause localized infections, with subsequent effects on survival and growth. Despite the significant impacts of RIFAs in regions where they have been introduced, very little is known about the competitive mechanisms of RIFAs with other species in their native habitat. We tested whether the survival and growth of hatchlings of the broad-snouted caiman Caiman latirostris were affected by different exposure times to RIFAs.

Results: We observed that an increased exposure time to RIFAs caused a decrease in C. latirostris survival. However, the subsequent growth of $C$. latirostris hatchlings was not affected by the time of exposure to the ants.

Conclusions: $S$. invicta can cause negative effects for other species in places where it is native. The mechanisms of S. invicta toxicity to caimans are not known; these data could help model the effects of S. invicta on C. latirostris survival, in turn fostering a better understanding of wild population dynamics.
\end{abstract}

Keywords: Reproduction; Growth; Venom; Colony; Nest; Ecology

\section{Background}

The red imported fire ant (RIFA) Solenopsis invicta is a globally invasive species, in part because it lives in high densities and may dominate potential food sources (Vinson 1994; Holway et al. 2002). The species is omnivorous, opportunistic, and exploits recently disturbed habitats by searching for food sources through a pheromonal pathway (Tschinkel et al. 1995; Taber 2000). The species utilizes a foraging distance of around $40 \mathrm{~m}$ from the mound (Martin et al. 1998). Evolution has modified the ants' sting in various ways to produce chemical substances to inject in, smear upon, or expel predators and potential competitors (Hölldobler and Wilson 1990). Unlike many other ants, S. invicta only uses its jaws to grip, and instead uses its abdominal petiole to inject 0.01 to $0.11 \mu \mathrm{l}$ of poison

\footnotetext{
* Correspondence: virginiapara2@yahoo.com.ar

${ }^{1} \mathrm{CIC}$ y TTP - CONICET, Dr. Materi y España, Diamante, Entre Ríos 3105, Argentina

¿2aboratorio de Zoología Aplicada, Anexo Vertebrados (FHUC-UNL/MASPyMA), Proyecto Yacaré - Aristóbulo del Valle 8700, Santa Fe 3000, Argentina

Full list of author information is available at the end of the article
}

(Tschinkel 2006). Furthermore, these ants use their poison for prey capture in territorial disputes and for colony defense (Haight and Tschinkel 2003).

During larval production, S. invicta searches for foods that contain a higher proportion of protein (Cook et al. 2010). This period coincides with the breeding season of various oviparous vertebrates. The texture and stiffness of certain bird and reptile eggs seem to play an important role in the ability of vertebrates to resist $S$. invicta (Diffie et al. 2010). However, during hatching or when young leaves the nest, vertebrate young may receive numerous stings (Allen et al. 2004; this study). Thus, RIFAs negatively affect some species, especially ground-nesting species including some amphibians, birds, and reptiles (Montgomery 1996; Tuberville et al. 2000). Most research on the effects of RIFAs on vertebrates was conducted in habitats where $S$. invicta is invasive, because the species has been implicated in the decline of populations of native species through competition and predation (Caughley and Gunn 1996; Wojcik et al. 2001; Holway et al. 2002). Other authors also described the impacts of RIFA species on sea- and freshwater turtles in the USA (Allen et al. 2001). 
At turtle nest sites, soil disturbance associated with digging of the nest chamber, combined with the production of mucus at laying time, attracts S. invicta to turtles' nesting sites. When hatching occurs, RIFAs attack turtle hatchlings, in turn increasing hatchling mortality or decreasing survivorship once they leave the nest (Allen et al. 2001).

The necrotic action of the venom can cause localized infections in vertebrates, with a subsequent effect on survival (Smith et al. 2007). S. invicta is also known to attack baby turtles Terrapene carolina triunguis, causing injuries that affect survival of the young (Parris et al. 2002). In hatchlings of the sea turtle species Caretta caretta, numerous injuries, including blindness and damage to fins caused by the necrotic action of the venom, were observed (Parris et al. 2002). Predation by RIFAs of cracked eggs of yellow-bellied turtles Trachemys scripta contributed to a hatchling mortality rate of $45 \%$ (Buhlmann and Coffman 2001). Other authors found that quail Colinus virginianus chicks exposed to RIFAs gained weight $15 \%$ more slowly than those with shorter exposure times and those with no exposure (Giuliano et al. 1996). In the US state of Texas, the decline in the quail population over the past 30 years has paralleled an expansion of the distribution of S. invicta (Allen et al. 1995). Similarly, reports of the presence of RIFAs were associated with a decline in populations of some snakes and lizards (Bartlett 1997; Nattrass and Vanderwoude 2001; Webb and Henke 2003). S. invicta was also implicated in the extinction of an arboreal snail (Orthalicus reses reses) in the USA (Forys et al. 2001). Despite the wide impacts of RIFAs in regions where they have been introduced, very little is known about competitive mechanisms in relation to other species in their native habitat (Calcaterra 2010).

In the USA, S. invicta colonizes alligator Alligator mississippiensis nests, attacking juveniles at the time of hatching and subsequently decreasing survival rates (Reagan et al. 2000). Stings by S. invicta also reduce growth rates in the same species (Allen et al. 1997). In Santa Fe Province, Argentina, the presence of RIFAs in Caiman latirostris nests was reported (Parachú Marcó and Piña 2008; Parachú Marcó et al. 2012), but possible localized effects of ant stings on hatchlings have not been tested. While a previous study showed a 21\% decrease in hatchling survival (Parachú Marcó 2011), some caimans were able to leave the nests infected by RIFAs. It is unclear whether the ability of caimans to leave infected nests ensures the survival of those individuals, as they can be seriously affected as a result of injuries and/or infections caused by S. invicta stings. Thus, in this work, we tested whether exposure of C. latirostris hatchlings to RIFAs affected their survival and growth.

\section{Methods}

S. invicta colonies were collected in the Zoological Experimental Station area of Santa Fe Province, Argentina, approximately 3 weeks before the caimans hatched. $S$. invicta individuals were placed in closed plastic trays and fed with glucose (a $20 \%$ solution). We used caiman hatchlings from four different clutches harvested in the wild during the 2005 to 2006 season and six clutches each from the 2006 to 2007, 2007 to 2008, and 2008 to 2009 seasons. In the last season (2008 to 2009), we measured the effect on survival in six clutches. Only three of these clutches were used to measure subsequent growth, because blood was collected from the other three clutches for corticosterone determination, and this procedure could have affected growth due to stress (Lance and Elsey 1999). However, it is known that the bleeding process does not affect survival, so we used all caiman clutches (Sheriff et al. 2011).

All the animals were treated following the Reference ethical framework for biomedical research: ethical principles for research with laboratory, farm and wild animals (National Scientific and Technical Research Council 2005), using noninvasive techniques and minimizing stress and suffering by suitable management methods. Immediately after hatching, the caimans were individualized with a colored thread tied around the chest area (a different color for each treatment). This was used to avoid excessive handling. Individuals from each clutch were divided into five treatments of six animals that were exposed to $S$. invicta for different times, leaving an unexposed group as the control. Each clutch of caimans was exposed to a single colony of $S$. invicta to prevent a potential genetic clutch effect. Individuals of the same clutch were placed in a tray with a colony of RIFAs, and after completing the required treatment time, the animals were passed to a tray with water in order to remove the ants.

In the first season (2005 to 2006), the animals were introduced to a RIFA colony, for $1,2,4$, and $6 \mathrm{~min}$, respectively. These times were determined arbitrarily based on an estimated time range that would take hatchlings to leave the nest. Previous records only mentioned that the time it takes caimans to hatch (i.e., leave the egg) after the initiation of vocalization ranged 12 to $24 \mathrm{~h}$ (Watanabe 1980; Platt et al. 2008). Those records did not note the time required to leave the nest. After the time of exposure to RIFA colony had lapsed, the animals were removed and washed with water. The animals were similarly handled and washed in the control treatment, except that there was no contact with RIFAs. Shorter periods of exposure to RIFAs colonies $(0.5,1,2$, and 4 min) were used in the 2006 to 2007,2007 to 2008 , and 2008 to 2009 seasons, and the 6-min treatment was omitted due to the fact that it resulted in the immediate death of hatchlings.

Twenty-four hours after the exposure, all the hatchlings were weighed, the snout-vent length (SVL) was recorded, and they were individually identified (with a 
numbered metal caravan) on each hind limb (size 1005-1, Monel Natl. Band and Tag, Newport, KY, USA). The hatchlings were placed in plastic trays with water and fed ad libitum by routine techniques (Larriera 1991). In the 2006 to 2007 season, the animals were raised for 2 months to monitor their survival. During this period, their length was measured, and they were weighed on days 15 and 45 to determine if growth was affected by ant exposure. During the following seasons (2007 to 2008 and 2008 to 2009), the hatchlings were only measured every 2 weeks in the first month after treatment to determine whether the ant attacks had produced an immediate negative effect on initial growth.

Data were analyzed using an analysis of variance (ANOVA), where the treatment (time of exposure to RIFAs) was the grouping variable, and the survival of each nest in each treatment (as a proportion between 0 and 1) was the response variable. For the weight and SVL analyses (Final measurement - Initial measurement) of the animals, we used an analysis of covariance (ANCOVA), in which the treatment was the grouping variable, the initial weight or initial SVL was the covariable, and the increase in weight or SLV was the response variable. Measurements are expressed as an average \pm standard error (SE). We used $p \leq 0.05$ to determine the statistical significance in all the tests performed.

In 2007 to 2008, we additionally collected the remaining RIFAs into wash trays and counted them to see if there was any relationship between the number of ants that had been in contact with the caimans and the number of hatchling deaths recorded per clutch. To do this, we used wire netting $(0.14 \times 0.50 \mathrm{~mm})$ to sieve the RIFAs from the solution of each treatment. RIFAs were then stored in a
$70 \%$ alcohol solution and later counted with the assistance of a magnifying glass (at $\times 6$ magnifications). We performed a linear regression between the number of ants counted (the same nests were washed into the same tray) and the number of hatchling deaths recorded for each nest.

\section{Results}

Differences were found in C. latirostris hatchling survival rates with different times of exposure to RIFAs. By analyzing all seasons (2005 - 2006 - 2008 to 2009), we observed that increasing the time of exposure to RIFAs caused a decrease in $C$. latirostris survival $(p=0.0001)$ (Figure 1). In the 2- and 4-min treatments, the hatchling survival rates ranged $35 \%$ to $50 \%$, although there was variability between nests used in each season for the same treatment. In contrast, the control treatment showed nearly $100 \%$ caiman survival (98\%). There was no hatchling survivorship in the 6-min treatment of contact with RIFAs. However, the exact causes of death (such as poisoning or general stress response caused by RIFAs) were not determined.

The hatchlings exposed to 2-, 4-, and 6-min treatments of RIFAs had a $100 \%$ mortality rate in the 2005 to 2006 season, with the 6-min treatment being the only treatment that produced immediate mortality (Table $1(\mathrm{~A})$ ). Of the 80 animals used in the experiments, only 16 hatchlings from the control treatment and 12 from the 1-min treatment survived. For this reason, it was not possible to analyze the effect of S. invicta stings on subsequent growth. In the 2006 to 2007 and 2007 to 2008 seasons, the hatchling survival was influenced by treatments ( $p=0.0038$ and 0.0139 , respectively). Survival

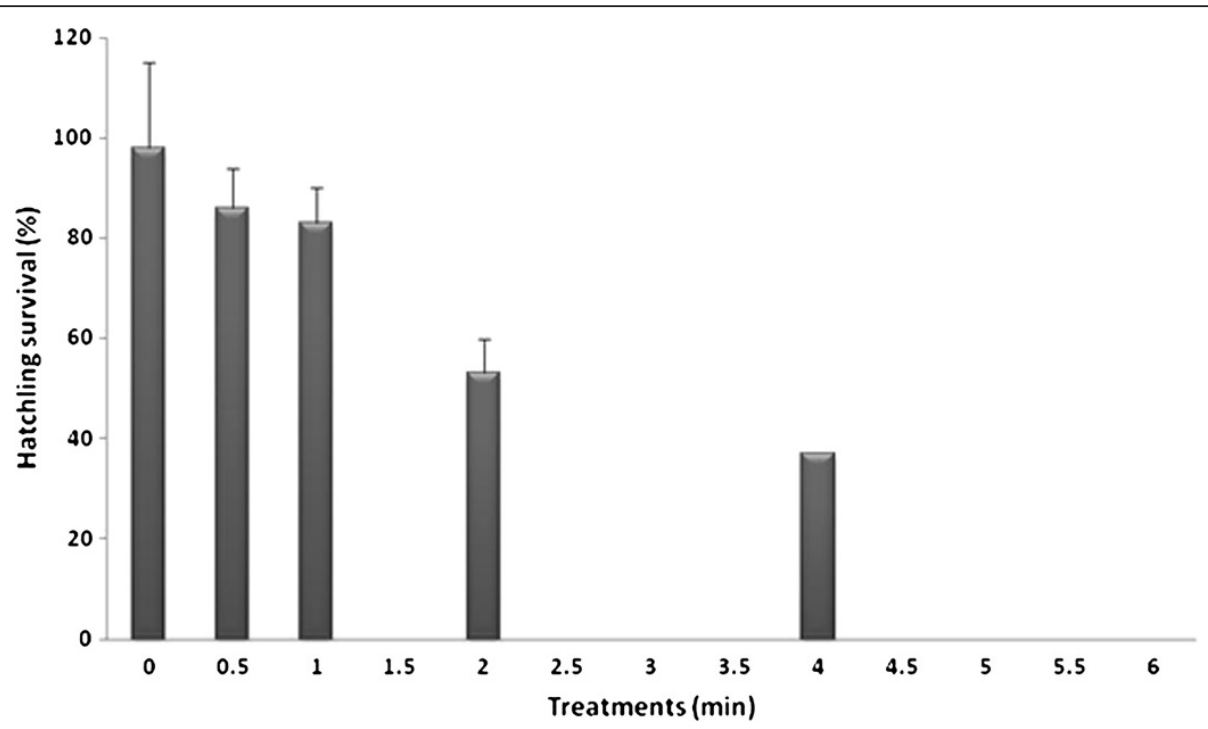

Figure 1 Percentage of hatchling survival for each treatment of time of exposure to S. invicta. 
Table 1 Number of animals used per time treatment ${ }^{\mathrm{a}}$ and survival (\%) per experimental treatment in each season

\begin{tabular}{ccccc}
\hline Season & $\begin{array}{c}\text { Treatment } \\
\text { (min) }\end{array}$ & $\begin{array}{c}\text { Animals } \\
\text { per } \\
\text { treatment }\end{array}$ & $\begin{array}{c}\text { Live animals } \\
\text { after } \\
\text { treatment }\end{array}$ & $\begin{array}{c}\text { Proportion of } \\
\text { hatchling } \\
\text { survival ( } \pm \text { SE) }\end{array}$ \\
\hline A (2005 to 2006) & 0 & 16 & 16 & 1 \\
& 1 & 16 & 12 & $0.73 \pm 0.16$ \\
2 & 16 & 0 & 0 \\
4 & 16 & 0 & 0 \\
6 & 16 & 0 & 0 \\
& Total & 80 & 28 & 0.35
\end{tabular}

B (2006 to 2007)

$\begin{array}{cccc}0 & 30 & 28 & 0.93 \pm 0.07 \\ 0.5 & 29 & 20 & 0.7 \pm 0.17 \\ 1 & 29 & 24 & 0.83 \pm 0.08 \\ 2 & 30 & 17 & 0.57 \pm 0.20 \\ 4 & 29 & 3 & 0.13 \pm 0.13 \\ \text { Total } & 147 & 92 & 0.63\end{array}$

C (2007 to 2008)

$\begin{array}{cccc}0 & 18 & 18 & 1 \\ 0.5 & 18 & 16 & 0.89 \pm 0.07 \\ 1 & 18 & 14 & 0.78 \pm 0.16 \\ 2 & 18 & 7 & 0.39 \pm 0.20 \\ 4 & 18 & 6 & 0.33 \pm 0.21 \\ \text { Total } & 90 & 61 & 0.68\end{array}$

D (2008 to 2009)

\begin{tabular}{cccc}
0 & 18 & 18 & 1 \\
0.5 & 18 & 18 & 1 \\
1 & 18 & 17 & 0.94 \\
2 & 18 & 18 & 1 \\
4 & 18 & 16 & 0.89 \\
Total & 90 & 87 & 0.97 \\
\hline
\end{tabular}

${ }^{\mathrm{a}}$ Those individuals which survived S. invicta bite exposure.

decreased as the exposure time increased. In 2006 to 2007, there were differences among individuals exposed for $4 \mathrm{~min}$ in relation to the $30-\mathrm{s}, 1-\mathrm{min}$, and control treatments (Table 1(B)), while the 4-min treatment only differed from the control treatment in 2007 to 2008 (Table $1(C)$ ). However, in 2008 to 2009, there was no difference in the survival of hatchlings exposed to different treatments $(p=0.5355)$ (Table 1(D)).

Considering all of the data, year by year, or all years combined in a single analysis, there was no effect of RIFA attacks on caiman growth $(p \geq 0.05)$. The number of ants recovered from the body of hatchlings was not related to the total number of dead hatchlings per nest $(p=0.1767)$.

\section{Discussion}

The potential effects of RIFAs on vertebrates in habitats where they are not native include direct impacts on survival, indirect effects on weight and growth, infections or irritation of the skin caused by ant stings, reduced prey numbers for other invertebrates and vertebrates, and possible changes in behavior that could affect subsequent survival (Allen et al. 2004). This work confirms that $S$. invicta can also cause negative effects in places where it is native. The first experiments of direct impacts of RIFAs on herpetofauna were conducted on the American alligator A. mississippiensis. The results of a laboratory experiment reported that exposure to $S$. invicta can cause the immediate death of hatchlings and can effect long-term survival (Allen et al. 1997). In the present study, we found that an increase in the time of exposure to RIFAs decreased hatchling survival in $C$. latirostris (Figure 1). It is still not known if hatchling deaths were caused by the ant venom, stress caused by stings, or a combination of both factors.

The data from this study could help model the effects of S. invicta on C. latirostris survival, in turn fostering a better understanding of wild population dynamics. However, not all animals were affected in the same way, particularly after the 2- and 4-min treatments. This indicates large variability in responses to treatments among clutches. It is possible that individual clutches had different levels of venom resistance, subsequently showing different levels of tolerance to ant stings. This may in turn have produced differences in survival between clutches. Therefore, declines in survivorship of C. latirostris hatchlings might be related to the exposure time to RIFAs and also to other factors such as individual variability within a population. Conversely, ant densities may differ among colonies, thus enabling a greater amount of stings during the same exposure time. However, no relationship was found between the number of RIFAs inside trays and hatchling mortality per nest in the 2007 to 2008 season. Another explanation could be related to varying levels of aggressiveness found among the S. invicta colonies (Morel et al. 1990; Vander Meer and Alonso 2002).

Chicks of the northern bobwhite C. virginianus stung by $S$. invicta exhibited a decrease in survival rates and also a reduction in weight gain (Giuliano et al. 1996). This survival reduction was also reported in other species of birds and reptiles (Buhlmann and Coffman 2001; Parris et al. 2002; Drees and Gold 2003). In the US, 20\% of A. mississippiensis nests were colonized by S. invicta. At least $50 \%$ of the surviving hatchlings showed evidence of ant attacks such as visible pustules and swelling of the fingers and eyes (Reagan et al. 2000). Allen et al. (1997) found that neonates exposed to RIFAs weighed 5\% less than those not in contact with S. invicta. As was 
reported for alligators (Allen et al. 1997), we speculated that a large percentage of the population of caimans in the wild may suffer the effects of ant stings, consequently affecting their survival. However, unlike the American alligator, the data presented in this study experimentally showed that ant stings did not produce negative effects on growth in body mass or SVL in neonates of $C$. latirostris. In addition, in contrast to what was observed in other species, only some individuals expressed pustules in membrane areas and the eyes, which disappeared a few days after treatment without affecting subsequent survival. We reported colonization rates two times higher than that reported in A. mississippiensis (Parachú Marcó et al. 2012). However, the lack of localized effects (infections or growth reduction) in C. latirostris hatchlings may have been due to a higher tolerance that caimans have developed after many years of receiving pressure from this insect in an area were the colonization rate of caiman nests by RIFAs can be high. This tolerance may allow $C$. latirostris hatchlings to recover more quickly after being stung.

Competition naturally occurs between living organisms which coexist in the same environment. The advantage of RIFAs in habitats where this species is invasive is related to the relative lack of competitors, predators, and pathogens. However, the expansion of this ant is associated with disturbed habitats and low diversity (Allen et al. 2004; Tschinkel 2006). Thus, the constant modification of habitats due to advancing agriculture and intensive farming, close to areas where both species coexist, could result in a decreased number of suitable nesting environments for $C$. latirostris. This could simultaneously reduce the reproductive choices of $C$. latirostris while favoring RIFA expansion. This could increase the rate of colonization in C. latirostris nests by RIFAs and in turn reduce the survival of $C$. latirostris hatchlings.

RIFAs are able to colonize over $50 \%$ of caiman nests (average among season $32.5 \% \pm 23.3 \%$ ) in Santa Fe, Argentina (Parachú Marcó et al. 2012). On average, $C$. latirostris hatching success declined by $43 \%$, corresponding to a $14.5 \%$ direct effect (ants killing hatchlings) and a 28.5\% indirect effect (ants preventing nest care and assistance by caiman females and consequent embryo death; Parachú Marcó 2011). Deaths due to RIFA attacks could be as high as $14 \%$ during an average season. However, the hatchlings that leave their nest also have been exposed to $S$. invicta stings, reducing their survivorship. Thus, considering the time of exposure to RIFAs, the subsequent survival of $C$. latirostris hatchlings may decrease by $14 \%$ to $66 \%$ (minimum and maximum times used that showed survivors, respectively), representing an additional $2.5 \%$ to $12 \%$ mortality. This may result in a total decline in reproduction of $16 \%$ to $26 \%$ due to RIFAs in an average year, depending on the time required by hatchlings to leave the nest (Figure 2).

\section{Conclusions}

In conclusion, considering the mean percentage of caiman nests colonized by RIFAs (32.5\%), the consequences of ant attacks in nests (43\%; Parachú Marcó pers. comm.), and post-hatching effects (14\% to $66 \%$, this

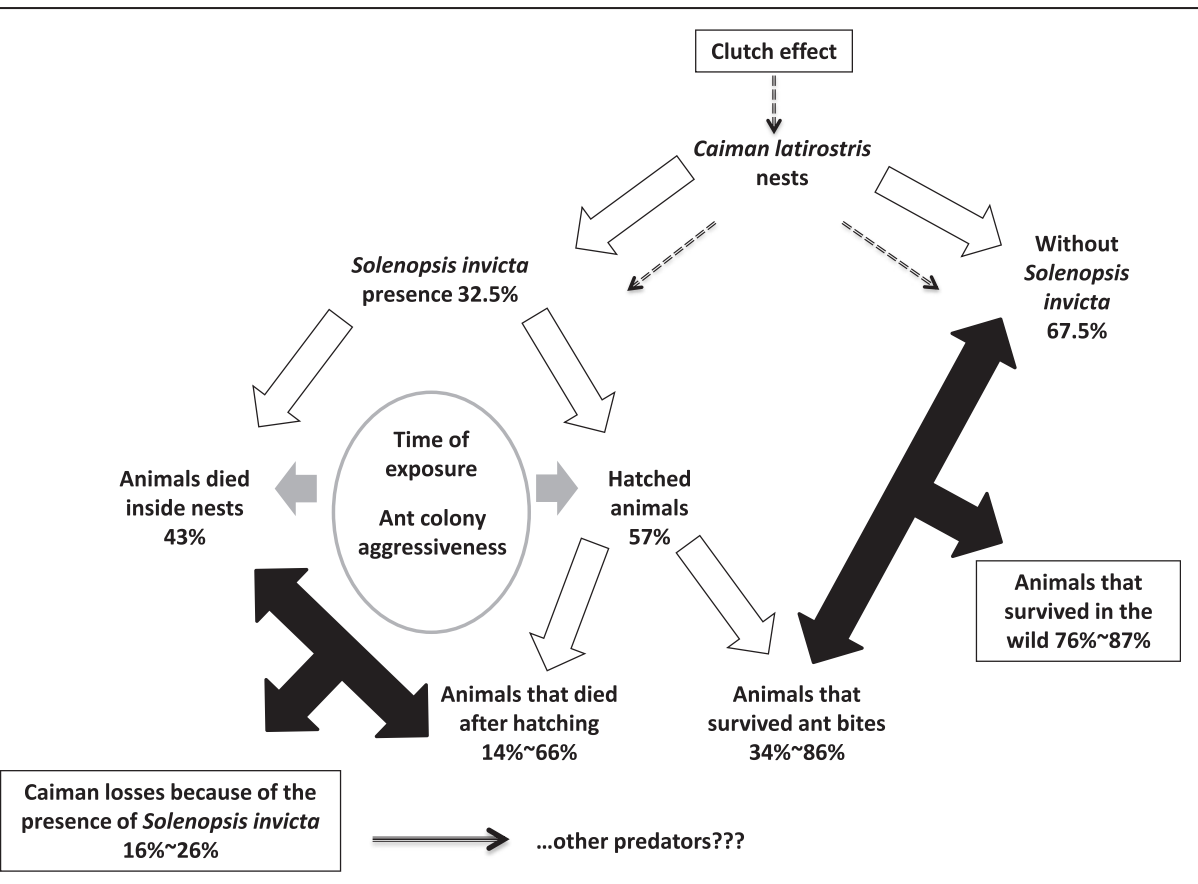

Figure 2 S. invicta effects on Caiman latirostris reproduction. 
work), it is estimated that $C$. latirostris loss caused solely by $S$. invicta could reach $16 \%$ to $26 \%$ in each breeding season, regardless of the factors that may be underestimating these percentages (Figure 2). Given that in Santa $\mathrm{Fe}$, Argentina the colonization of nests can exceed $50 \%$ in some seasons (Parachú Marcó et al. 2012), RIFA attacks could be responsible for a reduction of up to $40 \%$ of the nesting success of caimans. Understanding the relationships of RIFAs with caimans and other species in their native areas is therefore important when discussing nesting ecology. Relevant information on the reproductive biology of $C$. latirostris can be used to inform the sustainable management of the species, especially considering that $S$. invicta is just one of several nest predators of wild C. latirostris populations.

\section{Competing interests}

The authors declare that they have no competing interests.

\section{Authors' contributions}

All the authors performed the field experiments, participated and coordinated in the design and analysis of the study, and drafted the manuscript. All authors read and approved the final manuscript.

\section{Acknowledgments \\ We thank the other members of Proyecto Yacaré and the gauchos who helped with data collection, and M.E. Merchant, J. Addison, and B. Jirosova for the review of the English language used in the manuscript. This study was partially supported by Proyectos de Investigación Científica y Tecnológica (PICT) 2008 (grant numbers 0404 and 0220) and Proyectos Federales de Innovación Productiva (PFIP) 2008. MVPM is a post-doctoral fellow from Consejo Nacional de Investigaciones Científicas y Tecnológicas (CONICET). This is contribution no. 91 from Proyecto Yacaré}

\section{Author details}

${ }^{1}$ CIC y TTP - CONICET, Dr. Materi y España, Diamante, Entre Ríos 3105, Argentina. ${ }^{2}$ Laboratorio de Zoología Aplicada, Anexo Vertebrados (FHUC-UNL/MASPyMA), Proyecto Yacaré - Aristóbulo del Valle 8700, Santa Fe 3000, Argentina. ${ }^{3}$ Facultad de Humanidades y Ciencias, Universidad Nacional del Litoral, Santa Fe 3000, Argentina. ${ }^{4}$ Facultad de Ciencias y Tecnología (Subsede Diamante), Universidad Autónoma de Entre Ríos, Rios 3105, Argentina. ${ }^{5}$ Facultad de Ciencias de la Alimentación, Universidad Nacional de Entre Ríos, Rios 3200, Argentina.

Received: 28 March 2013 Accepted: 22 August 2013

Published: 9 December 2013

\section{References}

Allen CR, Lutz RS, Demarais S (1995) Red imported fire ant impacts on Northern Bobwhite populations. Ecol Appl 5:632-638

Allen CR, Rice KG, Wojcik D, Franklin Percival H (1997) Effect of red imported fire ant envenomization on neonatal American alligators. J Herpetol 31:318-321

Allen CR, Forys EA, Rice KG, Wojcik DP (2001) Effects of fire ants (Hymenoptera: Formicidae) on hatching turtles and prevalence of fire ants on sea turtle nesting beaches in Florida. Fla. Entomol 84:250-253

Allen CR, Epperson DM, Garmestani AS (2004) Red imported fire ant impacts on wildlife: a decade of research. Am Midl Nat 152:88-103

Bartlett D (1997) 40 years of thoughts on Payne's Prairie. Reptiles 68:70-73

Buhlmann KA, Coffman G (2001) Fire ant predation of turtle nests and implications for the strategy of delayed emergence. J Elisha Mitch Sci Soc 117:94-100

Calcaterra LA (2010) Solenopsis invicta en Argentina: sus interacciones con hormigas competidoras y moscas parasitoides (Pseudacteon spp.). PhD dissertation. Universidad Nacional de Buenos Aires, Buenos Aires, Argentina

Caughley G, Gunn A (1996) Conservation biology in theory and practice. Blackwell, Cambridge, pp 71-147
Cook SC, Eubanks MD, Gold RE, Behmer ST (2010) Colony-level macronutrient regulation in ants: mechanisms, hoarding and associated costs. Anim Behav 79:429-437

Diffie S, Miller J, Murray K (2010) Laboratory observations of red imported fire ant (Hymenoptera: Formicidae) predation on reptilian and avian eggs. J Herpetol 44:294-296

Drees BM, Gold RE (2003) Development of integrated pest management programs for the red imported fire ant (Hymenoptera: Formicidae). J Entomol Sci 38:170-180

Forys EA, Allen CR, Wojcik DP (2001) The likely cause of extinction of the tree snail Orthalicus reses reses (Say). J Mollusc Stud 67:369-376

Giuliano WM, Allen CR, Lutz RS, Demarais S (1996) Effects of red imported fire ants on northern bobwhite chicks. J Wildlife Manage 60:309-313

Haight KL, Tschinkel WR (2003) Patterns of venom synthesis and use in the fire ant Solenopsis invicta. Toxicon 42:673-682

Hölldobler B, Wilson EO (1990) The ants. Harvard University Press, Cambridge

Holway DA, Lach L, Suarez AV, Tsutsui ND, Case TJ (2002) The causes and consequences of ant invasions. Annu Rev Ecol Syst 33:181-233

Lance VA, Elsey RM (1999) Plasma catecholamines and plasma corticosterone following restraint stress in juvenile alligators. J Exp Zool 283:559-565

Larriera A (1991) Cría en granjas: una alternativa de manejo para los caimanes argentinos (revisión bibliográfica). Rev Argentina Prod Anim 11:479-484

Martin JB, Drees BM, Grant WE, Pedersen EK, Barr CL, Vinson SB (1998) Foraging range of the polygynous form of the red imported fire ant, Solenopsis invicta Buren. Southwest Entomol 23:221-228

Montgomery WB (1996) Predation by the red fire ant, Solenopsis invicta, on the three-toed box turtle, Terrapene carolina triunguis. B Chicago Herp Soc 31:105-106

Morel L, Vander Meer RK, Lofgren CS (1990) Comparison of nest mate recognition between monogyne and polygyne populations of Solenopsis invicta (Hymenoptera: Formicidae. Ann Entomol Soc Am 83:642-647

National Scientific and Technical Research Council (2005) Reference ethical framework for biomedics research: ethical principles for research with laboratory, farm and wild animals. Res Nro. 1047 Anexo II. CONICET, Buenos Aires

Nattrass R, Vanderwoude C (2001) A preliminary investigation of the ecological effects of fire ants (Solenopsis invicta) in Brisbane. Ecol Manage Rest 2:220-223

Parachú Marcó MV (2011) Efecto de las hormigas coloradas (Solenopsis invicta) sobre los nidos y el crecimiento post-natal del yacaré overo (Caiman latirostris). PhD dissertation. Universidad Nacional de Córdoba, Córdoba

Parachú Marcó MV, Piña Cl (2008) Hormigas coloradas (Solenopsis invicta Buren, Hymenoptera: Formicidae) en nidos de yacaré overo Caiman latirostris; Crocodylia: Alligatoridae. ¿Aleatorio o elección? In: Aceñolaza FG (ed) Temas de la biodiversidad del litoral III. INSUGEO, Miscelánea, Tucumán, pp 201-209

Parachú Marcó MV, Larriera A, Piña Cl (2012) Presence of red fire ants (Solenopsis invicta Buren) in broad-snouted caiman (Caiman latirostris) nests. J Herpetol 46:228-232

Parris LB, Lamont MM, Carthy RR (2002) Increased incidence of red imported fire ant (Hymenoptera: Formicidae) presence in loggerhead sea turtle (Testudines: Cheloniidae) nest and observations of hatchling mortality. Fla Entomol 85:514-517

Platt SG, Rainwater TR, Thorbjarnarson JB, McMurry ST (2008) Reproductive dynamics of a tropical freshwater crocodilian: Morelet's crocodile in northern Belize. J Zool 275:177-189

Reagan SR, Ertel JM, Wright VL (2000) David and Goliath retold. Fire ants and alligators. J Herpetol 34:475-478

Sheriff M, Dantzer B, Delehanty B, Palme R, Boonstra R (2011) Measuring stress in wildlife: techniques for quantifying glucocorticoids. Oecologia 166:869-887

Smith JE, Whelan CJ, Taylor SJ, Denight ML, Stake MM (2007) Novel predator-prey interactions: Is resistance futile? Evol Ecol Res 9:433-446

Taber SW (2000) Fire ants. Texas A\&M University Press, College Station

Tschinkel WR (2006) The fire ants. Belknap Harvard University Press, Cambridge

Tschinkel W, Adams E, Macom T (1995) Territory area and colony size in the fire ant Solenopsis invicta. J Anim Ecol 64:473-480

Tuberville TD, Bodie JR, Jensen JB, LaClaire L, Whitfield GJ (2000) Apparent decline of the southern hog-nosed snake, Heterodon simus. J Elisha Mitch Sci Soc 116:19-40

Vander Meer RK, Alonso LE (2002) Queen primer pheromone affects conspecific fire ant (Solenopsis invicta) aggression. Behav Ecol Sociobiol 51:122-130 
Vinson SB (1994) Impact of the invasion of Solenopsis invicta Buren on native food webs. In: Williams DF (ed) Exotic ants: biology, impact, and control of introduced species. Westview, Boulder, pp 240-258

Watanabe ME (1980) The ethology of the American alligator, Alligator mississippiensis with emphasis on vocalizations and responses to vocalizations. PhD dissertation. New York University, New York

Webb SL, Henke SE (2003) Defensive strategies of Texas horned lizards (Phrynosoma cornutum). Herpetol Rev 34:327-328

Wojcik DP, Allen CR, Brenner RJ, Forys EA, Jouvenaz DP, Lutz RS (2001) Imported fire ants: impacts on biodiversity. Am Entomol 47:16-23

doi:10.1186/1810-522X-52-52

Cite this article as: Marcó et al:: Impacts of red imported fire ants

Solenopsis invicta on survivorship of hatchlings of the broad-snouted

caiman Caiman latirostris. Zoological Studies 2013 52:52.

\section{Submit your manuscript to a SpringerOpen ${ }^{\circ}$} journal and benefit from:

- Convenient online submission

- Rigorous peer review

- Immediate publication on acceptance

- Open access: articles freely available online

- High visibility within the field

- Retaining the copyright to your article

Submit your next manuscript at $>$ springeropen.com 